\title{
Bathing in good evidence
}

\author{
Tom Moberly UK editor
}

The BMJ

Most clinical trials don't help patients, at least if we accept Paul Glasziou and Iain Chalmers's claim that over $80 \%$ of research is wasted (http://blogs.bmj.com/bmj/2016/01/14/paul-glasziouand-iain-chalmers-is-85-of-health-research-really-wasted). A wide range of approaches, from curiosity driven studies to basic clinical science, have a place in medical research, but too often trials do not set out to answer important clinical questions.

Too many trials do not use outcomes of direct relevance to patients, relying instead on surrogate measures. Too often the harms of treatment are not adequately assessed. And too much research never sees the light of day. And too often improvements in care are not introduced because they are too expensive or require services to be redesigned.

A trial we publish this week is therefore well worth reading. It takes a common problem and reports outcomes that matter to patients, partly because the researchers used patients' views to inform their research. The trial concludes that pouring emollient additives into the bath gives no benefit to children with eczema (doi:10.1136/bmj.k1332).

Eczema affects one in five children in the UK, and emollients form the mainstay of treatment. I should declare an interest here. I was a child with eczema, and adding emollient to warm running water was a key part of my bath time routine.
This latest study leaves some questions unanswered, as one of the authors points out in a BMJ Opinion piece (http://blogs.bmj. com/bmj/2018/05/02/miriam-santer-patient-and-carer-choicein-emollients-for-eczema-treatment-is-crucial). These include whether bath emollients are easier to use than leave-on emollients. The study also did not include infants, so further research will need to examine whether they might benefit, as the authors of the accompanying editorial point out (doi:10. 1136/bmj.k1791).

This week's issue also reflects on the case of Alfie Evans, the nearly 2 year old with severe brain damage who was at the centre of a fight between his parents and doctors. Clare Dyer reports that doctors are working with parents, lawyers, and others to improve the handling of disputes over children's treatment (doi:10.1136/bmj.k1895), and Margaret McCartney considers how arguments arising from religious beliefs are used to push the case for intervention (doi:10.1136/bmj.k1896).

Prolonged disputes are devastating for families and traumatic for medical and nursing staff. "There are no winners, only losers," say our editorialists Dominic Wilkinson and Julian Savulescu (doi:10.1136/bmj.k1891). "There is a pressing need for professionals to come together with families to explore and implement new constructive solutions to avoid, mitigate, and resolve disagreements about treatment." 